Nevşehir Bilim ve Teknoloji Dergisi Cilt 6(1) 93-101 2017

DOI: 10.17100/nevbiltek.296685

URL: http://dx.doi.org/10.17100/nevbiltek.296685

\title{
Davranışsal Pediatrik Besleme Değerlendirmesi Ölçeği (DPBDÖ)’ni Türkçe’ye Uyarlama Çalışması
}

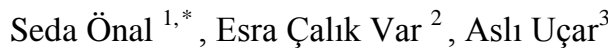 \\ ${ }^{1}$ Ankara Üniversitesi, Sağllk Bilimleri Fakültesi, Beslenme ve Diyetetik Bölümü, Ankara \\ ${ }^{2}$ Yıldırım Beyazıd Üniversitesi, Sağlık Bilimleri Fakültesi, Sosyal Hizmet Bölümü, Ankara \\ ${ }^{3}$ Ankara Üniversitesi, Sağlık Bilimleri Fakültesi, Beslenme ve Diyetetik Bölümü, Ankara \\ $\ddot{O} \mathbf{z}$
}

Bu çalışma, pediatride yeme davranışını saptamak amacıyla kullanılan, ebeveynin yanıtladı̆̆ı, Behavioral Pediatrics Feeding Assessment Scale (BPFAS)'ın Türkçe'ye uyarlanması amacıyla planlanmış ve yürütülmüştür. Çalışma 2 ilkokul ve 2 anaokul toplam 4 okulda eğitim gören çocukların ebeveynleri (n:241) çalışma örneklemini oluşturmuştur. Çalışmaya gönüllü olarak katılmayı kabul eden ebeveynler toplamda 241 kişidir. Ebeveynlere ölçek formu uygulanmıştır. Ebeveynlere ve çocuklara ait demografik özellikler ve BPFAS'ın Türkçe'ye çevrilmiş şekli olan, Davranışsal Pediatrik Besleme Değerlendirmesi Ölçeği (DPBDÖ) sorgulanmıştır. DPBDÖ’nin Türkçeye uyarlama çalışmaları için iki dili de iyi konuşan ve anlayan, uzmanlığı İngilizce olan öğretim görevlileri tarafından İngilizce'den Türkçe'ye çevrilmiş, ardından tekrar İngilizce'ye çevrilmiş ve maddeler karşılaştırılmıştır. Gerekli düzeltmeler yapıldıktan sonra form tekrar Türkçe'ye çevrilmiştir. Karar verilen maddeler 8 alan uzmanının görüşüne sunulmuş ve ölçeğe son hali verilmiştir. Uygulamaların ardından çocuğa ait olan 25 madde için geçerlik güvenirlik analizleri yapılmış, Türk toplumuna uygunluğu sınanmıştır. Ölçeğin 24 madde dört alt boyutlu versiyonu için Cronbach $\alpha=.88$ olarak bulunmuştur. Ayrıca, ölçeğin test-tekrar test güvenirliği de .88 olarak bulunmuştur. Ölçeğin yapı geçerliğini belirlemek amacıyla doğrulayıcı faktör analizi yapılmıştır. Ölçeğin değerlendirilmesinde; ölçekten alınan puan arttıkça, yeme sorunlarının arttığı yorumu yapılmaktadır. Yapılan istatistiksel analizler sonucunda, BPFAS'dan Türkçe’ye uyarlanan (DPBDÖ)'nin Türkiye’de uygulanabilir, geçerli ve güvenilir bir ölçme aracı olduğu belirlenmiştir.

Anahtar Kelimeler: Davranışsal Pediatrik Besleme Değerlendirmesi Ölçeği (DPBDÖ), Geçerlilik, Güvenirlik, Yeme Bozukluğu, Beslenme

\section{Adapting Behavioral Pediatric Feeding Assessment Scale (BPFAS) to Turkish}

Abstract

This research is planned and conducted to evaluate validity and reliability of adaptation of Behavioral Pediatrics Feeding Assessment Scale, which is used to detect eating behaviors in pediatrics and answered by parents, into Turkish. The research sample is the parents of children selected from 2 primary schools and 2 kindergardens in total. Parents who voluntarily participate in this research are 241 individuals in total. The scale form has been applied to the parents. The Turkish version of Behavioral Pediatric Nutrition Assessment Scale (BPFAS), was questioned for demographic characteristics of parents of children. In the context of adapting BPFAS to Turkish, the scale is translated first from English to Turkish; and then translated back to English by specialists whose proficiency is in English; and items are compared. After the necessary corrections were made, the form was translated back into Turkish. The scale is finalized after receiving feedbacks on the decided items from 8 specialist of this area. Following the applications, validity and reliability evaluations were completed by testing its appropriateness for Turkish. The Cronbach alpha index was found as .88 for all 24 items of the scale with four factor version. Moreover, the correlation index for test-retest reliability of the scale is found as .88. Confirmatory factor analysis was performed to determine the validity of the scale. When evaluating the scale, it was commented that as the points received from the scale increase, the level of eating disorders also increase. As a result of the statistical analysis, it was determined that BPFAS adapted to Turkish (DPBDÖ) is a valid and reliable measurement tool for Turkey.

Keywords:, Behavioral Pediatrics Feeding Assessment Scale (BPFAS), validity, reliability, eating disorder, nutrition

*e-mail: onals@ankara.edu.tr 


\section{Giriş}

Çocuklar için yemek yemeyi öğrenmek, birçok biyomedikal, fizyolojik, çevresel ve sosyokültürel / bağlamsal faktörlerden etkilenen karmaşık bir süreçtir [1]. Bu öğrenme döneminde, bazı zor mizaçlı çocukların, açlık ve tokluk sinyalleri yerine, duygusal tetikleyicilere tepki gösteren yeme davranışları geliştirebileceği ve bu durumun obezite için risk oluşturacağı tahmin edilmektedir [2]. Son dönemlerde obezitenin yanında, iştahsızlık ve yeme problemleri de çocuk beslenmesinde önemli bir sorun olarak ortaya çıkmakta ve bu nedenlerle doktora başvuran çocukların oranı \%20-35 arasında değişmektedir [3].İ̧̧tahsızlık; aile, çevre ve çocukla ilgili faktörlere bağlı gelişebilmektedir [4]. Ailelerin yiyeceklerin çeşitlerini veya miktarlarını sınırlandırması ve çocukların yeme kontrolünü geliştirme girişimi, çocukların aşırı yemesi veya acıkmadan yemesiyle dolayısıyla da vücut ağırlığı ile ilişkilendirilmektedir [5-6]. Çocuklarda görülen bu sorunların etiyolojisi tam olarak anlaşılamamış olmakla birlikte; genetik, sosyo - kültürel ve psikolojik, davranışsal faktörlerden etkilendiği tahmin edilmektedir [7-8].

Son dönemlerde nedeni tam olarak anlaşılamayan yeme davranışlarını ve türlerini belirlemek önem kazanmıştır [9-10]. Yeme davranışları üzerine yapılan araştırmaların çoğu anne odaklı yapılmakta ve çocuklarının beslenmeleri hakkındaki endişelerini belirlemeye çalışmaktadır. Anneler, yeme problemi olan çocuklarının, yeme bozukluğunun çocuklarına olumsuz etkilerini önlemek veya bunlara değinmek için tedavi arayışlarına yönelmiştir [11]. Çünkü yeme bozukluğu riski taşıyan çocukların en kısa sürede belirlenmesi ve önleme programlarının uygulanmasının daha sonraki yıllarda oluşabilecek yeme bozukluğu riskini azaltabileceği görüşü hakimdir [12]. Yeme bozukluklarını belirlemede, klinik yöntemler, anket çalışmaları veya biyokimyasal belirteçler kullanılmakla birlikte, ölçek kullanımı da bireyleri farklı yönlerden değerlendirme imkânı sunmaktadır. Tespit için faydalanılan bilgi, tutum ve davranış ölçekleri, doğrudan ölçülemeyen öznel bazı özelliklerin nicel hale getirilerek ölçülebilmesinde kullanılmaktadır [13]. Çocukluk döneminde yeme bozukluklarını değerlendirmede ölçek kullanımı yol gösterici olmaktadır [14]. Behavioral Pediatrics Feeding Assessment Scale (BPFAS) çocukluk döneminde kullanılan yeme davranış ölçeklerinden biridir [15] ve şu anda yayınlanan en yüksek psikometrik profili olan ölçü olarak görülmektedir [16]. Bu çalışmada, pediatride olumsuz yeme davranışını saptamak amacıyla kullanılan, ebeveynlerden birinin yanıtladığı, BPFAS’in Türkçe’ye uyarlanması ve çocuklarda görülen yeme davranışlarının belirlenmesi amaçlanmıştır.

\section{Materyal ve Metot}

\section{Araştırma Örneklemi}

Bu çalışmanın örneklemini; Şubat-Eylül 2016 tarihleri arasında Ankara ilinde yer alan Milli Eğitim Bakanlığı'na bağlı 2 anaokulu ve 2 ilkokulda eğitim gören çocuğu olan gönüllü olarak çalışmaya

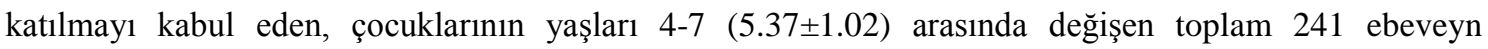
oluşturmuştur. Çocukların yaşları ise arasında değişmektedir. Okullardan alınacak örneklem için küme örnekleme yöntemi kullanılmıştır. Okulların anasınıfı ve sınıf öğretmenleri ile görüşülmüş, anketler zarf içinde, çalışmayı anlatan bir yazı ile birlikte öğrenciler aracılığı ile velilere ulaştırılmıştır. Bir hafta sonra gönderilen anket formları toplanmıştır. 350 anket öğrencilerle gönderilmiş ve geri alınan ve tam olarak doldurulduğu belirlenen 241 anket üzerinden değerlendirme yapılmıştır. Gereken tüm bu faktör 
analizlerinin yapılabilmesi için ölçekte yer alan madde sayısının 5-10 katı kadar kişiye ulaşılması önerilmektedir [17]. Ölçek 35 ifadeden oluştuğu için geri gelen anket sayısı yeterli olmuştur. Bu çalışmada Ankara Üniversitesi Klinik Araştırmalar Etik Kurulu'ndan 04-132-16 sayılı ve 22 Şubat 2016 tarihli "Etik Kurul Onayı" alınmıştır.

\section{Ölçek Formu}

Türkçe'ye uyarlama çalışması yapılan Davranışsal Pediatrik Besleme Değerlendirmesi Ölçeği (DPBDÖ), Crist ve arkadaşları tarafından geliştirilmiş olup 5'li Likert tipi bir ölçektir. Ölçeğin Türkçe'ye uyarlanması için gerekli izin yazarlardan yazılı olarak alınmıştır. Ölçek 35 maddeden oluşmaktadır. Ancak ölçekteki ifadelerin 25 tanesi çocuğun beslenme durumuna, 10 tanesi ise çocuğun beslenmesinden sorumlu olan kişiye ilişkindir. Bu nedenle ölçeği geliştiren yazarların önerisi ve diğer dillere yapılan uyarlama çalışmaları da göz önüne alınarak $[18,19]$ Türkçe'ye uyarlama çalışması da sadece çocuğun beslenme durumuna ilişkin olan 25 madde üzerinden yapılmıştır. Ölçekte yer alan ifadeler 1 ile 5 arasında puanlandırılmaktadır (1=Asla, 2=Nadiren, 3=Bazen, 4=Sıklıkla 5=her zaman). Ölçekten alınacak puanlar 35-175 arasında değişmektedir. Ölçekten alınan puandaki artış yüksek seviyede sorun teşkil eden yeme davranışını ve beslenme alışkanlığını göstermektedir. DPBDÖ’nün çocuklarla ilgili olan 25 maddesinin, 6 tanesi pozitif $(1,3,5,6,9$, ve 16 . maddeler), 19 tanesi negatif anlam taşımaktadır. Pozitif olarak ifade edilen maddeler tam tersi şekilde puanlandırılmaktadır.

Orijinal ölçekte beş alt boyut yer almaktadır. Yiyecek seçiciliği alt boyutunda 7 madde, erken dönem yiyecek reddi alt boyutunda 5 madde, erken dönem pütürlü yiyecek reddi alt boyutunda 4 madde, geç dönem yiyecek reddi alt boyutunda 6 madde ve yemekte oyalanma alt boyutunda 3 madde yer almaktadır.

Yapılan geçerlik ve güvenirlik çalışmalarının ardından uzman görüşü de alınarak ölçeğin dört alt boyutlu olmasına karar verilmiştir. Yiyecek seçiciliği alt boyutunda 7 madde, erken dönem yiyecek reddi alt boyutunda 5 madde, erken dönem pütürlü yiyecek reddi alt boyutunda 5 madde, geç dönem yiyecek reddi alt boyutunda 7 madde yer almaktadır.

\section{DPBDÖ'nün Dil Geçerliliği}

Ölçeğin Türkçe'ye uyarlanması amacıyla ölçekteki ifadeler uzmanlığı İngilizce olan 2 öğretim üyesi tarafından Türkçe'ye çevrilmiş, daha sonra yine aynı şekilde bir başka öğretim üyesi tarafından İngilizce'ye çevrilmiştir. Çeviriler karşılaştırılarak aralarındaki tutarlılıklar incelenmiş, gerekli düzeltmeler yapıldıktan sonra tekrar Türkçe'ye çevrilmiştir. Daha sonra oluşturulan bu ölçekte yer alan ifadelerin; çocuklar açısından uygulanabilirliği konunun uzmanı 8 öğretim üyesinin görüşlerine sunulmuştur. Elde edilen Uzman Değerlendirme Formları ile ölçekte gerekli düzenlemeler yapılmıştır.

\section{Verilerin İstatistiksel Olarak Değerlendirilmesi}

Çalışmadan elde edilen verilerin değerlendirilmesi için gerekli istatistik programlarından yararlanılmıştır. Ölçeğin alt boyutlarının teorik modele uyumunu analiz edebilmek için kullanılan Doğrulayıcı Faktör Analizi yöntemi için AMOS programı kullanılmıştır.

Ölçeğin güvenirlik çalışmaları için test tekrar test korelasyonu, madde toplam korelasyonu ve cronbach $\alpha$ hesaplanmıştır. Ölçeğin yapı geçerliği ve Türkiye'de uygulanabilirliği doğrulayıcı faktör analizi ile sınanmıştır. Bütün istatistiksel analizlerde önemlilik düzeyi olarak $\mathrm{p}<0.05$ olarak kabul edilmiştir. 


\section{Bulgular}

\section{DPBDÖ’nün Güvenirlik Çalışması}

Ölçeğin güvenirliği için iki ayrı yönteme başvurulmuştur. Bunlardan biri test-tekrar test yöntemidir. Bu amaçla 51 ebeveyne 2 hafta arayla iki kez uygulanmıştır. Katılımcıların ölçekten aldıkları puanlar arasındaki korelasyon .88 olarak bulunmuştur. $\mathrm{Bu}$ sonuç, ölçeğin farklı zamanlarda uygulanmasıyla elde edilen puanları arasında oldukça yüksek bir tutarlılık gösterdiğini vurgulamaktadır. İkinci yöntem olarak ölçeği oluşturan maddelerin iç tutarlılığını veren Cronbach $\alpha$ hesaplanmıştır.

Ölçeğin orijinal formunda yer alan beş faktörlü yapısı için iç tutarlılığın ne düzeyde olduğu, madde toplam korelasyonları ve Cronbach Alfa iç tutarlılık katsayıları ile incelenmiş ve Tablo 1'de gösterilmiştir. Buna göre DPBDÖ’nin bütünlüğü için 5 alt boyutlu için Cronbach $\alpha \quad 87$ olarak bulunmuştur. Güvenirlik katsayısının .70 üzerinde olması ölçeğin güvenilir olduğunu göstermektedir.

Ölçeğin orijinal beş faktörlü yapısında 24 maddenin toplam puan korelasyonu pozitif ve .20’nin üzerindedir. Ancak 4. Faktörde yer alan çocuğun yaşı maddesinin madde toplam korelasyonu .14 olarak belirlenmiştir. Ölçeğin alt boyutları için Cronbach $\alpha$ hesaplanmış, yiyecek seçiciliği için .76, erken dönem yiyecek reddi için .74, erken dönem pütürlü yiyecek reddi için .72, geç dönem yiyecek reddi için .69, yemekte oyalanma alt boyutu için .33 bulunmuştur.

Yukarıdaki tabloda görüldüğü gibi çizelge incelendiğinde madde toplam test korelasyonlarının .14 ile .66 arasında değiştiği görülmektedir.

Ölçeğin orijinal formunda, yemekte oyalanma isimli 5. faktör altına 2 madde yerleştirilmiştir. Her bir faktör altında 3 madde bulunması gerekmektedir, ayrıca yemekte oyalanma alt boyutunun Cronbach $\alpha$ nın .33 olması nedeniyle alan uzmanlarının görüşüne başvurulmuştur. Beşinci alt boyuttaki 8 . ve 22. maddeler 4.alt boyuta eklenmesine karar verilmiştir. Ayrıca madde toplam korelasyon katsayısı .14 olan çocuğun yaşı kabul sınırı olan .20’den düşük olduğu için uzman görüşü alınarak ölçekten çıkarılmıştır. Ölçeğin 4 boyutlu versiyonu için güvenirlik analizleri tekrarlanmıştır.

Tablo 1. DPBDÖ’nün 4 Alt Boyutlu Madde Analizi Sonuçları

\begin{tabular}{|c|c|c|}
\hline \multirow[t]{2}{*}{ Alt boyutlar ve maddeler } & \multicolumn{2}{|c|}{$\begin{array}{c}\text { Madde-alt boyut toplam } \\
\text { puan korelasyonu } \\
\text { Cronbach's }\end{array}$} \\
\hline & r & Alpha $(\alpha)$ \\
\hline \multicolumn{3}{|l|}{ Yiyecek seçiciliği } \\
\hline 1.Meyve yer & .51 & \\
\hline 3.Yemek yerken eğlenir & .56 & \\
\hline 5.Yeni yiyecekleri denemeye çalışır & .26 & .76 \\
\hline 6.Et veya balık yer & .62 & \\
\hline 9.Yemek vakitlerine hazır olur & .63 & \\
\hline 16.Sebze yer & .42 & \\
\hline 18.Nişastalı (patates, noodle gibi) ürünleri yer & .31 & \\
\hline \multicolumn{3}{|l|}{ Erken dönem yiyecek reddi } \\
\hline 7.Bir yemeği bitirmesi 20 dakikadan fazla zaman alır & .40 & \\
\hline 15.Yemek zamanlarında mızmızlanır veya ağlar & .66 & \\
\hline 17.Yeme zamanlarında öfke nöbeti geçirir & .48 & .74 \\
\hline 19.İştahsızdır & .59 & \\
\hline 20.Yiyecekleri tükürür & .42 & \\
\hline
\end{tabular}




\begin{tabular}{ll}
\hline Erken dönem pütürlü yiyecek reddi & \\
2.Yiyecekleri çiğnemede güçlük yaşar & .59 \\
4.Yemek zamanında öğürür ve nefesi kesilir & .55 \\
11.Yemek öncesi, yemek sırasında veya sonrasında kusar & .31 \\
12.Sadece öğütülmüş, süzülmüş veya yumuşak şeyleri yer & .42 \\
14.Yiyecekleri ağzında bekletir, yutmaz & .55 \\
Geç dönem yiyecek reddi & \\
8.Süt içer & .72 \\
10.Yeme vakitleri dışında abur cubur yer & .20 \\
13.Yemek sırasında masadan kalkar & .54 \\
21.Konuşarak yemeyi geciktirir & .55 \\
22.Katı yiyecekler yerine sıvı yiyecekleri tercih eder & .40 \\
23.Yemek yemeyi reddeder fakat yemekten hemen & .54 \\
yemeyi ister & .62 \\
24.Ne yiyip ne yemeyeceği konusunda tartışmaya çalışır & .59 \\
\hline
\end{tabular}

Ölçeğin alt boyutlarının cronbach $\alpha$ 'nın .70 'den büyük oluşu ve madde toplam korelasyon yüklerinin .20 'den yüksek olduğu gözlenmiştir. Süt içer maddesinin madde toplam korelasyon katsayısı .20 olarak bulunmuş ve uzman görüşüyle ölçekte kalmasına karar verilmiştir. Ölçeğin 4 boyutlu yapısının güvenilir olduğunu göstermiştir. Ölçek için yapılan güvenirlik çalışmasının ardından doğrulayıcı faktör analizi yapılmıştır.

\section{DPBDÖ'nün Geçerlik Çalışması için Yapılan Doğrulayıcı Faktör Analizi Çalışması}

Doğrulayıcı faktör analizi (DFA), önceden oluşturulan bir modelde gözlenen değişkenleri baz alarak gizil değişken (faktör) oluşturmaya yönelik bir analizdir. Bir ölçeğin faktör yapısının kuramsal bilgilere uygun olması geçerlik ve güvenirlik çalışmalarında istenmektedir. Bir testin standartlaştırılması için, indeks veya ölçeğin değişik ana kütlelerde geçerlik ve güvenirliklerinin yapılması gerekmektedir. Bu standartlaştırma sürecinde DFA, bireylerden toplanan verilerden elde edilen bulguların teorik yapıyla uyum gösterip göstermediğini inceleyebilen bir yöntem olup, kültürler arası geçerlik güvenirlik çalışmalarında mutlaka yapılması gereken bir analizdir [20-21].

Çok değişkenli bir analiz tekniği olan doğrulayıcı faktör analizini yapabilmek için çok değişkenli istatistik tekniklerinin varsayımlarını yerine getirmek gerekmektedir. Bu bağlamda veriler örneklem büyüklüğü, çoklu normal dağılım, doğrusallık, çoklu bağlantı ve uç değerler açısından incelenmiştir. Çalışma grubunun büyüklüğünü değerlendirmek için Kaiser Mayer Olkin (KMO) değeri incelenmiştir. $\mathrm{Bu}$ değerin yüksek olması ölçekteki, her bir değişkenin diğer değişkenler tarafindan mükemmel bir şekilde tahmin edilebileceği anlamına gelir [22]. Analiz sonucunda KMO değeri .87 olarak bulunmuş ve uygun görülmüştür. Çoklu normal dağılımın değerlendirilmesinde ise Barlett küresellik testi kullanılmıştır ve normallik varsayımının karşılandığı yorumu yapılmıştır [23].

Ölçeğin, yapı geçerliğini ve toplanan verinin modele uygunluğunu saptamak üzere DPBDÖ’nin DFA yapılmıştır. Veriler AMOS programı ile analiz edilmiştir. Modelin 4'lü faktör yapısına ilişkin uyum istatistikleri Tablo 2'de ve uyum şeması Şekil 1'de gösterilmiştir. 


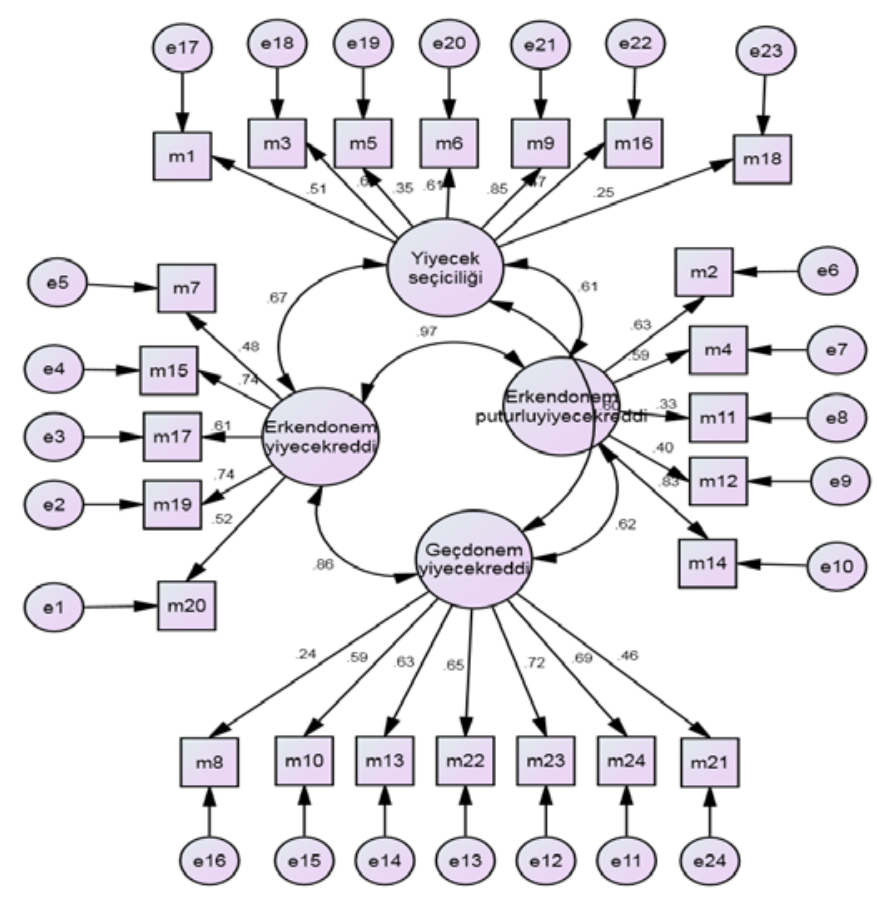

Şekil 1. DPBÖ’nün Doğrulayıcı Faktör Analizi Diagramı

Tablo 2. DPBDÖ’nün faktör yapısı için iyilik uyum indeksleri

\begin{tabular}{|c|c|c|c|c|c|c|c|c|}
\hline Model & $\kappa^{2}$ & Sd & $\boldsymbol{s}^{2} / \mathbf{s d}$ & $\mathbf{P}$ & IFI & GFI $^{*}$ & $\mathrm{CFI}^{* *}$ & RMSEA*** \\
\hline Kavramsal model & 592.522 & 246 & 2.40 & 0,00 & 0.85 & 0.90 & 0.85 & 0.07 \\
\hline
\end{tabular}

Çizelge ve şekil incelendiğinde model ve veri arasındaki uyumun yüksek olduğu görülmektedir. Ki-kare değerinin serbestlik derecesine bölümünden elde edilen $\aleph^{2} / \mathrm{df}$ oran 2.40 'tır. Buna ek olarak model-veri uyumu göstergelerinden olan CFI .85, örneklemden bağımsız olarak SRMR değerinin olasılığını veren uyum indeksi GFI'nın .90 olması da model ve veri uyumunun kabul edilebilir olduğunu göstermiştir. RMSEA’nın .08'den küçük olması modelin iyi uyumunu göstermektedir. DPBDÖ’nin dört boyutlu yapısının güvenilir ve geçerli sonuçlar verebileceği sonucuna ulaşılabilir. Bu veriler 1şığında modelin iyi uyum gösterdiği yorumu yapılmıştır.

\section{Tartışma ve Sonuç}

$\mathrm{Bu}$ araştırmanın amacı Crist ve arkadaşları [15] tarafından geliştirilen Davranışşsal Pediatrik Besleme Değerlendirmesi Ölçeğinin Türkçe’ye uyarlanması ve çocuklarda görülen yeme davranışlarının belirlenebilmesidir. Yeme davranışı literatürde yeme zamanlarında gösterilen davranışlar olarak ifade edilmektedir ve konu ile ilgili araştırmalar gün geçtikçe daha fazla ilgi çekmektedir. Bu bağlamda bundan sonra yapılacak araştırmalarda kullanılmak üzere DPBDÖ’nün Türkçe’ye uyarlanması önem teşkil etmektedir. Ölçeğin uyarlama çalışması ölçeğin Türkçe’ye çevrilmesi ile başlamış, pilot çalışma ve asıl uygulama çalışmaları ile devam etmiştir. Çalışmanın örneklemini anaokulu ve ilkokulda eğitim gören çocuğu olan gönüllü 241 ebeveyn oluşturmuştur. Ölçeğin değerlendirilmesinde öncelikle güvenirlik 
analizleri yapılmıştır. Ölçeğin güvenirliği ilk olarak ölçeğin beş faktörlü yapısı ile sınanmış, madde toplam korelasyonu .20'nin altında olan yaş maddesi ölçekten çıkarılmış ayrıca iki maddeden oluşan beşinci faktörün güvenirlik kat sayısının güvenirlik kabul katsayısının altında çıkması ve iki maddeden oluşması nedeniyle uzman görüşü alınarak dördüncü faktörle birleştirilmiştir. Ölçeğin en son karar verilen maddelerle dört boyutlu versiyonu için toplam Cronbach $\alpha 0.88$ alt boyutlar için cronbach $\alpha, .76, .74, .72$ ve .77 olarak bulunmuştur. Bu bulgular ölçeğin güvenilir olduğunu göstermektedir. Diğer bir güvenirlik analizi madde toplam katsayısı puanları ise $.20-.66$ arasında değişmektedir. Bu durum ölçeğin pediatrik beslenme davranışını güvenilir olarak ölçebilecek düzeyde olduğu anlamına gelmektedir.

Ölçeğin Türkiye'de uygunluğunu belirleyebilmek amacı ile yapılan doğrulayıcı faktör analizi sonuçları arasında yer alan Ki-kare değerinin serbestlik derecesine bölümünden elde edilen $x^{2} / \mathrm{df}$ oranı 2.40, GFI'nın 90 olması da model ve veri uyumunun kabul edilebilir olduğunu göstermiştir. RMSEA'nın .07 olması modelin Türkiye’ye uygunluğunu göstermektedir.

Sonuç olarak DPBDÖ’nin uyarlanması sırasında belli bazı sınırlılıklara sahip olduğu düşünülmektedir. Çalışma daha büyük örneklem gruplarıyla tekrarlanabilir. $\mathrm{Bu}$ araştırma ile ülkemize çocuklarda yeme davranışını tespit etmede kullanılabilecek bir ölçme aracı kazandırılmıştır. DPBDÖ’nün; obezite ve malnutrisyonun yaygın olduğu ülkemizde yeme davranışı tespiti gibi son derece önemli bir konuya dikkat çektiği düşünülmektedir.

Ölçeğin, çocuklarda obeziteye veya iştahsızlığa eğilimi ve ileriki dönemlerde bunlara bağlı oluşabilecek çeşitli sorunları önceden belirlediği, bu şekilde bu durumlara karşı gerekli önlemlerin alınmasına yardım edebileceği düşünülmektedir. DPBDÖ, hem sağlıklı çocuklarda olumsuz yeme davranışlarını, hem de yeme bozukluğu olan çocukları belirlemede iyi sonuçlar verebilir. Uyarlanan bu ölçme aracı çocuklarda yeme davranışı sorunlarına karşı önlem almada, hem ailelere hem de konunun uzmanlarına yol gösterici olacağı düşünülmektedir.

\section{Teşekkür}

$\mathrm{Bu}$ çalışmanın yürütülmesini sağlayan Milli Eğitim Bakanlığı, İl Milli Eğitim Genel Müdürlüğüne, yardımları için ilkokul ve anaokulu öğretmenlerine ve yöneticilerine, çalışmaya katılmayı kabul eden ebeveynlere teşekkür ederiz.

\section{Kaynaklar}

[1] González M. L., Stern, K. "Co-occurring behavioral difficulties in children with severe feeding problems: A descriptive study” Research in Developmental Disabilities, 58, 45-54, 2016

[2] Tate A. D., Trofholz A., Rudasill K. M., Neumark-Sztainer D., Berge, J. M. "Does child temperament modify the overweight risk associated with parent feeding behaviors and child eating behaviors?: An exploratory study” Appetite, 101, 178-183, 2016

[3] Temizel İ. N. S. "İştahsız çocuk” Çocuk Sağlığı ve Hastalıkları Dergisi, S, 51, 176-181, 2008

[4] Ünal F. "İştahsız Çocuklara Klinik Yaklaşım” Güncel Pediatri, 1(9), 79-84, 2011

[5] Saltzman J. A., Liechty J. M., Bost K. K., Fiese B. H. "Parent binge eating and restrictive feeding practices: Indirect effects of parent's responses to child's negative emotion” Eating Behaviors, 21, 150-154, 2016 
[6] Schmid, R., Richter R., Brauhardt A., Hiemisch A., Kiess W., Hilbert A. "Parental feeding practices in families with children aged 2-13 years: Psychometric properties and child agespecific norms of the German version of the Child Feeding Questionnaire (CFQ)” Appetite, 109, 154-164, 2017

[7] Bozan N., “Hollanda yeme davranışı (debq) anketinin Türk üniversite ögrencilerinde geçerlilik ve güvenirliğinin sinanması” Başkent Üniversitesi, Sağlık Bilimleri Enstitüsü, Yüksek Lisans Tezi, 17s, Ankara, 2009

[8] Bandstra N. F., Crist W. B., Napier-Phillips A., Flowerdew, G. "The impact of behavioral feeding intervention on health care utilization” Children's Health Care, 40(4), 282-296, 2011

[9] Erge S. “Obezitede Diyet Tedavisini Destekleyen Davranışsal Tedavi” Turkish Journal of Endocrinology and Metabolism, 2, 75-82, 2003

[10] Crist W., Dobbelsteyn C., Brousseau A. M., Napier-Phillips, A. "Pediatric assessment scale for severe feeding problems: validity and reliability of a new scale for tube-fed children” Nutrition in Clinical Practice, 19(4), 403-408, 2004

[11] Lydecker J. A., Grilo, C. M. "Fathers and mothers with eating-disorder psychopathology: Associations with child eating-disorder behaviors” Journal of Psychosomatic Research, 86, 6369, 2016

[12] Siyez, D. "Yeme bozukluğu olan çocuklar ve ergenler etiyolojisi ile ilgili çalışmalar, müdahale, değerlendirme ve tedavi” Dokuz Eylül Üniversitesi Buca Ĕ̆itim Fakültesi Dergisi, 20, 21-27, 2006

[13] Erkorkmaz Ü., Yılmaz R., Demir O., Sanisoğlu S. Y., Etikan İ., Özçetin M. “Çocuklarda yeme davranışı ile ebeveyn besleme tarzı arasındaki ilişkinin kanonik korelasyon analizi ile incelenmesi” Turkiye Klinikleri Journal of Medical Sciences, 33(1), 138-148, 2013

[14] Kurt E., Örün E. "Yeme bozukluğu olan çocuğa yaklaşım" Journal of Current Pediatrics/Guncel Pediatri, 14(3),129-135, 2016

[15] Crist W., Napier-Phillips A. "Mealtime behaviors of young children: a comparison of normative and clinical data” Journal of Developmental and Behavioral Pediatrics, 22(5), 279-286, 2001

[16] Dovey T. M., Jordan C., Aldridge V. K., Martin C. I. "Screening for feeding disorders. Creating critical values using the behavioural pediatrics feeding assessment scale” Appetite, 69, 108-113, 2013

[17] İncirkuş K., Nahcıvan N. "Kronik Hastalık Bakımını Değerlendirme Ölçeği-Hasta Formu'nun Türkçe Versiyonunun Geçerlik ve Güvenirliği’” Dokuz Eylül Üniversitesi Hemşirelik Yüksekokulu Elektronik Dergisi, 4 (1), 102-109, 2011

[18] Davis A. M., Canter K. S., Stough C. O., Gillette M. D., Patton S. "Measurement of mealtime behaviors in rural overweight children: An exploratory factor analysis of the behavioral pediatrics feeding assessment scale” Journal of Pediatric Psychology, 39(3), 332-339,2014

[19] Allen S. L., Smith I. M., Duku E., Vaillancourt T., Szatmari P., Bryson S., Roberts W. Behavioral Pediatrics Feeding Assessment Scale in young children with autism spectrum disorder: Psychometrics and associations with child and parent variables. Journal of Pediatric Psychology, 40(6), 581-590, 2015

[20] Çapık C. "Geçerlik ve güvenirlik çalışmalarında doğrulayıcı faktör analizinin kullanımı” Anadolu Hemşirelik ve Sağlık Bilimleri Dergisi, 17(3), 196-205, 2014 
[21] Çalık Var E. “Üniversite Öğrencilerinde Ve Mezunlarında Öğrenci Sadakatini Yordayan Değişkenlerin Yapısal Eşitlik Modellemesiyle İncelenmesi” Ankara Üniversitesi, Eğitim Bilimleri Enstitüsü, Doktora Tezi, 87s, Ankara, 2013

[22] Büyüköztürk Ş. “Sosyal Bilimler İçin Veri Analizi El Kitabı” Pegem A Yayıncılık, Ankara, 2006

[23] Çokluk Ö., Şekercioğlu G. ve Büyüköztürk Ş. (2010). "Sosyal bilimler için çok değişsenli istatistik. SPSS ve LISREL uygulamaları" Pegem A Yaylncllı, Ankara, 2010 